\title{
Influence of Lower Limb Muscle Fatigue on Balance Function
}

\author{
Kazuhisa Inoue, PT ${ }^{1,3)}$, Mitsutoshi Uematsu, PT, PhD ${ }^{2)}$, Hiroshi Maruoka, PT, $\mathrm{PhD}^{3)}$, \\ Kazuhiko Hara, PT, PhD ${ }^{3)}$, Naohiko Kanemura, PT, PhD ${ }^{3)}$, Tadashi Masuda, $\mathrm{PhD}^{4}$, \\ SAdAo Morita, MD, $\mathrm{PhD}^{5)}$ \\ 1) Graduate School of Medical and Dental Science, Tokyo Medical and Dental University: 820 \\ Sannomiya, Koshigaya, Saitama 343-8540, Japan. TEL: +81 48-973-4322, FAX: +81 48-973-4322, \\ E-mail: inoue-kazuhisa@spu.ac.jp \\ 2) Graduate School of Health Care Studies, Sijoh University \\ 3) Department of Physcial Therapy, Saitama Prefectural University \\ 4) Faculty of Symbiotic Systems Science, Fukushima University \\ 5) Department of Rehabilitation Medicine, Tokyo Medical and Dental University
}

\begin{abstract}
Purpose] Balance training lowers the risk of falling in the elderly, but it is not known which specific muscles should be strengthened. The purpose of this study was to determine associations between fatigue of individual muscle groups in the lower limbs and balance. [Subjects and Methods] We tested 42 lower limbs of 21 healthy young adults with no history of fractures or of bone and joint disorders. Groups of flexor and extensor muscles were fatigued individually by voluntary isometric contraction, and the effects on balance function were analyzed. [Results] We found changes in total trajectory length of hip extensors and ankle plantar flexors after muscles were fatigued and in trajectory length per unit area of hip flexors and extensors, knee flexors and ankle dorsiflexors. Only hip extensors showed changes in both total trajectory length and trajectory length per unit area. [Conclusion] The results of this study suggest that muscle fatigue of the hip extensors is associated with a decline in balance function of the lower limbs of healthy young adults. It is likely that incorporating a greater focus on hip extensors in balance training would increase the effectiveness of such programs.

Key words: Balance, Fall, Muscle fatigue
\end{abstract}

(This article was submitted Oct. 2, 2012, and was accepted Nov. 7, 2012)

\section{INTRODUCTION}

Seniors have an increased risk of falling during their daily activities. Elderly persons may lose balance and fall while walking or standing ${ }^{1,2)}$. A decline in balance function with aging increases the risk of falling, and balance training has been proven to lower this risk ${ }^{3-5)}$. A fall can result in various bone fractures, and the resulting increased care requirements may cause a loss of independence in daily living6). Prevention of falls in the elderly is therefore an important research area.

Studies of balance function have been used to help understand ways to prevent falls in the elderly ${ }^{7-10)}$. There is currently a diverse range of opinions on methods used to prevent the decline of balance function and on potential exercise programs to prevent falls ${ }^{3-5}$. Physical exercise programs to improve balance function have been proposed. Effective training methods include several weeks of balance training (squats, walking, jumping on a trampoline, ball exercises) and combinations of several types of training (such as inclusion of weight shift training for hemiplegic patients $)^{7-10)}$. However, previous studies have not indicated which specific muscles should be strengthened to improve balance function, and the balance training programs that have been proposed are not detailed enough.

The human body maintains its posture during walking or standing by collecting sensory input from the vestibular, visual and proprioceptive systems and processing this input in the central nervous system, which then acts on the locomotor system $^{11-13)}$. Many studies have reported on the influence of central nervous system disorders such as cerebral vascular disorders and Parkinson's disease in maintaining balance function. There are also reports describing the influence of various muscle groups in the trunk, lower limbs and upper limbs on balance ${ }^{14-16)}$

Yaggie et al. ${ }^{14)}$ reported a continuous decline in balance function for 10 minutes after ankle plantar flexors and dorsiflexors were fatigued by isokinetic exercises, and a recovery to normal after 20 minutes. Another study reported that fatigue of hip and knee joint muscles due to exercise had a larger impact on balance function than fatigue of ankle joint muscles ${ }^{15}$. Vuillerme et al. ${ }^{16)}$ fatigued muscles by asking subjects to continue voluntary exercise of both triceps surae muscles until they were unable to stand on their toes. Many past studies have indicated influences from ankle plantar flexor and dorsiflexor groups and knee extensor and flexor 
groups on balance. In some studies, both flexor and extensor groups were fatigued simultaneously or specific muscle groups in the lower limbs were fatigued. However, since individual muscle groups of the hip, knee and ankle joints were not individually fatigued, it remains unclear which muscle groups decrease balance function.

In this study, we individually fatigued the extensor and flexor groups acting on the lower limb joints by voluntary isometric contraction and examined which muscle groups caused a decrease in balance function. To minimize the risks associated with muscle fatigue, we used healthy young adults as subjects. The purpose of this study was to determine associations between fatigue of individual muscle groups in the lower limbs and balance. Increased understanding of the effects of muscle fatigue on the balance function of healthy young adults will contribute to the development of effective interventions for the prevention of falls in the elderly.

\section{SUBJECTS AND METHODS}

Approval for this study was obtained from the ethics committee of Saitama Prefectural University (approval no. 20072), and the study complied with the principles of the Declaration of Helsinki. We explained the purpose and procedures of the study to subjects and obtained their written consent. We tested 42 lower limbs of 21 healthy young adults (10 males aged $22.0 \pm 3.9$ years and 11 females aged $20.7 \pm$ 2.2 years) (Table 1 ) with no history of fractures or of bone and joint disorders.

First, the trajectory of the center of foot pressure of the subjects was measured while they were standing barefoot with feet together and eyes open for 30 seconds, using a stabilometer (Gravicorder GS5500, Anima Corp., Tokyo, Japan) with a sampling frequency of $50 \mathrm{~Hz}$. During measurement, the subjects were asked to look at a cross marked on a whiteboard at eye level. The distance between the subjects and the cross was about $2 \mathrm{~m}$. The total trajectory length $(\mathrm{cm})$ and the trajectory length per unit area $(1 / \mathrm{cm})$ were measured to provide an index of the trajectory of the center of pressure ${ }^{17)}$ The total trajectory length indicates the center of pressure trajectory during static balance, and trajectory length per unit area indicates the degree of proprioceptive posture control.

Using a multi-mode dynamometer (Biodex System 3, Biodex Medical Systems, Inc., Shirley, NY, USA), each of six muscle groups (hip extensors, hip flexors, knee extensors, knee flexors, ankle plantar flexors and ankle dorsiflexors) was individually fatigued with one voluntary isometric contraction exercise for one joint of one leg at a time. Table 2 indicates the joint positions during voluntary isometric contraction exercises. Maximum contraction was sustained until the muscles were fatigued and the strength decreased to $30 \%$ of the maximum or less ${ }^{18-20)}$. Only one muscle group was measured in any subject per day, and subjects were given at least 1 rest day between measurements so that temporary fatigue of muscle groups would not overlap. The trajectory of the center of pressure was measured immediately after the muscle group was fatigued and after 5, 15 and 60 minutes to analyze changes over time. Subjects sat on a chair and rested between measurements.
Table 1. Subject reference chart $(n=21)$

\begin{tabular}{lrrc}
\hline & \multicolumn{1}{c}{ Age $(\mathrm{yr})$} & Height $(\mathrm{cm})$ & Weight $(\mathrm{kg})$ \\
\cline { 2 - 4 } & Mean \pm SD & Mean \pm SD & Mean \pm SD \\
\hline Males $(\mathrm{n}=10)$ & $22.0 \pm 3.9$ & $177.2 \pm 4.6$ & $67.6 \pm 4.9$ \\
Females $(\mathrm{n}=11)$ & $20.7 \pm 2.2$ & $159.1 \pm 5.4$ & $53.5 \pm 8.1$ \\
\hline
\end{tabular}

For statistical analysis, the average of the left and right measurements was used. One-way repeated measures analysis of variance (ANOVA) using time since fatigue as a factor was performed using the SPSS version 17.0 software (SPSS Inc.). Tukey's test was used for multiple comparisons. The level of statistical significance was set at $\mathrm{p}<0.05$.

\section{RESULTS}

There were significant differences in the total trajectory lengths of hip extensors $(\mathrm{p}<0.05)$ and ankle dorsiflexors $(p<0.05)$ before and after fatigue. There were no significant differences between trajectory lengths before fatigue and 5 minutes or longer after fatigue.

There were significant differences in the trajectory lengths per unit area of hip flexors $(\mathrm{p}<0.05)$, hip extensors $(\mathrm{p}<0.05)$, knee flexors, $(\mathrm{p}<0.05)$ and ankle dorsiflexors $(p<0.05)$ before and after fatigue. The trajectory lengths per unit area of hip extensors showed a downward trend that lasted for 15 minutes (indicating muscle fatigue) and then increased significantly until 60 minutes after muscle fatigue (indicating recovery). The same tendency was observed in knee flexors and ankle dorsiflexors, but the significant downward trend continued only until 5 minutes after fatigue.

In this study, the hip extensors were the only muscle group in which significant differences were seen in both total trajectory length and trajectory length per unit area (Table 3).

\section{DISCUSSION}

The results of this study of healthy young adults suggest that fatigue of lower limb muscle groups can affect their balance function.

In contrast to this study, previous studies ${ }^{14-16)}$ measured displacement of the center of pressure using the trajectory of the center of pressure as the index. Our findings indicate that fatigue in hip and knee extensors and flexors as well as the muscles around the ankle joints significantly decreases balance function.

However, our findings are different from the results reported by Yaggie et al. ${ }^{14)}$ in terms of fatigue in the triceps surae muscles. In the present study, balance function was decreased only immediately after the muscles were fatigued, unlike previous studies that showed a decline lasting for 10 minutes. This is probably attributable to differences in experimental methods. This study used voluntary isometric contraction exercises, and previous studies used voluntary isokinetic contraction exercises. Voluntary isokinetic contraction exercises put a greater burden on muscles and 
Table 2. Joint positions during voluntary isometric contraction exercises

\begin{tabular}{lcccc}
\hline Muscles & Posture & Hip joint & Knee joint & Ankle joint \\
\hline HF & Supine & $90^{\circ}$ & $90^{\circ}$ & Plantar/dorsiflexion, neutral \\
HE & Supine & $30^{\circ}$ & $0^{\circ}$ & Plantar/dorsiflexion, neutral \\
KF & Sitting & $90^{\circ}$ & $70^{\circ}$ & Plantar/dorsiflexion, neutral \\
KE & Sitting & $90^{\circ}$ & $70^{\circ}$ & Plantar/dorsiflexion, neutral \\
APF & Sitting & $90^{\circ}$ & $20^{\circ}$ & Plantar/dorsiflexion, neutral \\
ADF & Sitting & $90^{\circ}$ & $20^{\circ}$ & $10^{\circ}$ plantar flexion \\
\hline
\end{tabular}

HF, hip flexors; HE, hip extensors; KF, knee flexors; KE, knee extensors; APF, ankle plantar flexors; ADF, ankle dorsiflexors

Table 3. Total trajectory length and trajectory length per unit area at different time points

\begin{tabular}{|c|c|c|c|c|c|c|}
\hline & (1) Pre & (2) Post & (3) 5 min post & (4) 15 min post & (5) 60 min post & Multiple comparison \\
\hline \multicolumn{7}{|c|}{ Total trajectory length } \\
\hline $\mathrm{HF}$ & $36.1 \pm 9.9$ & $\begin{array}{c}37.6 \pm 11.9 \\
(4.2)\end{array}$ & $\begin{array}{c}34.4 \pm 7.0 \\
(-4.6)\end{array}$ & $\begin{array}{c}35.4 \pm 8.7 \\
(-1.9)\end{array}$ & $\begin{array}{c}35.2 \pm 8.4 \\
(-2.3)\end{array}$ & N.S. \\
\hline $\mathrm{HE}$ & $34.0 \pm 9.6$ & $\begin{array}{c}37.7 \pm 13.3 \\
(10.6)\end{array}$ & $\begin{array}{c}34.6 \pm 7.8 \\
(1.6)\end{array}$ & $\begin{array}{c}34.4 \pm 8.1 \\
(1.1)\end{array}$ & $\begin{array}{c}35.5 \pm 10.2 \\
(4.2)\end{array}$ & $(2)>(1)^{*},(2)>(3)^{*},(2)>(4)^{*}$ \\
\hline $\mathrm{KF}$ & $35.8 \pm 10.5$ & $\begin{array}{c}37.0 \pm 10.5 \\
(3.4)\end{array}$ & $\begin{array}{c}36.3 \pm 9.6 \\
(1.4)\end{array}$ & $\begin{array}{c}34.1 \pm 8.3 \\
(-4.6)\end{array}$ & $\begin{array}{c}35.9 \pm 7.4 \\
(0.3)\end{array}$ & N.S. \\
\hline $\mathrm{KE}$ & $35.3 \pm 9.3$ & $\begin{array}{c}36.9 \pm 10.3 \\
(4.6)\end{array}$ & $\begin{array}{c}35.8 \pm 8.1 \\
(1.4)\end{array}$ & $\begin{array}{c}35.2 \pm 8.9 \\
(-0.4)\end{array}$ & $\begin{array}{c}34.3 \pm 7.9 \\
(-2.7)\end{array}$ & N.S. \\
\hline APF & $34.8 \pm 8.8$ & $\begin{array}{c}38.9 \pm 10.6 \\
(11.7)\end{array}$ & $\begin{array}{c}35.1 \pm 5.7 \\
(0.7)\end{array}$ & $\begin{array}{c}35.2 \pm 6.5 \\
(1.2)\end{array}$ & $\begin{array}{c}35.6 \pm 9.1 \\
(2.2)\end{array}$ & $(2)>(1)^{*},(2)>(3)^{*},(2)>(4)^{*},(2)>(5)^{*}$ \\
\hline $\mathrm{ADF}$ & $36.4 \pm 11.0$ & $\begin{array}{c}36.7 \pm 10.0 \\
(0.8)\end{array}$ & $\begin{array}{c}36.8 \pm 9.3 \\
(1.2)\end{array}$ & $\begin{array}{c}34.4 \pm 9.6 \\
(-5.4)\end{array}$ & $\begin{array}{c}36.5 \pm 9.9 \\
(0.4)\end{array}$ & N.S. \\
\hline \multicolumn{7}{|c|}{ Trajectory length per unit area } \\
\hline $\mathrm{HF}$ & $21.2 \pm 7.2$ & $\begin{array}{c}17.4 \pm 6.8 \\
(-17.8)\end{array}$ & $\begin{array}{c}19.6 \pm 7.9 \\
(-7.3)\end{array}$ & $\begin{array}{c}18.6 \pm 7.7 \\
(-12.2)\end{array}$ & $\begin{array}{c}19.9 \pm 7.8 \\
(-5.9)\end{array}$ & $(1)>(2)^{*}$ \\
\hline $\mathrm{HE}$ & $20.7 \pm 7.9$ & $\begin{array}{c}14.9 \pm 4.8 \\
(-27.8)\end{array}$ & $\begin{array}{c}16.9 \pm 6.1 \\
(-18.1)\end{array}$ & $\begin{array}{c}17.8 \pm 6.9 \\
(-13.8)\end{array}$ & $\begin{array}{c}19.4 \pm 6.9 \\
(-6.3)\end{array}$ & $\begin{array}{c}(1)>(2)^{*},(1)>(3)^{*},(1)>(4)^{*},(4)>(2)^{*}, \\
(5)>(2)^{*},(5)>(3)^{*}\end{array}$ \\
\hline KF & $21.4 \pm 8.9$ & $\begin{array}{c}16.5 \pm 5.9 \\
(-22.9)\end{array}$ & $\begin{array}{c}18.5 \pm 6.3 \\
(-13.6)\end{array}$ & $\begin{array}{c}18.7 \pm 8.9 \\
(-12.5)\end{array}$ & $\begin{array}{l}21.5 \pm 8.7 \\
\quad(0.4)\end{array}$ & $(1)>(2)^{*},(1)>(3)^{*},(5)>(2)^{*},(5)>(3)^{*}$ \\
\hline $\mathrm{KE}$ & $20.3 \pm 7.4$ & $\begin{array}{c}19.1 \pm 8.3 \\
(-5.8)\end{array}$ & $\begin{array}{c}20.6 \pm 7.8 \\
\quad(1.3)\end{array}$ & $\begin{array}{l}18.5 \pm 7.0 \\
(-8.7)\end{array}$ & $\begin{array}{c}19.1 \pm 7.3 \\
(-5.9)\end{array}$ & N.S. \\
\hline APF & $20.2 \pm 7.0$ & $\begin{array}{c}18.0 \pm 7.4 \\
(-11.1)\end{array}$ & $\begin{array}{c}18.5 \pm 6.3 \\
\quad(-8.8)\end{array}$ & $\begin{array}{c}17.2 \pm 7.2 \\
(-15.1)\end{array}$ & $\begin{array}{c}17.8 \pm 4.6 \\
(-12.2)\end{array}$ & N.S. \\
\hline $\mathrm{ADF}$ & $22.0 \pm 9.1$ & $\begin{array}{c}17.9 \pm 8.6 \\
(-18.9)\end{array}$ & $\begin{array}{c}19.0 \pm 7.5 \\
(-13.8) \\
\end{array}$ & $\begin{array}{c}19.8 \pm 8.5 \\
(-10.1) \\
\end{array}$ & $\begin{array}{l}20.2 \pm 8.4 \\
(-8.2)\end{array}$ & $(1)>(2)^{*},(1)>(3)^{*},(5)>(2)^{*}$ \\
\hline
\end{tabular}

*:p<0.05. HF, hip flexors; HE, hip extensors; KF, knee flexors; KE, knee extensors; APF, ankle plantar flexors; ADF, ankle dorsiflexors; pre, before fatigue, post, immediately post fatigue; $5 \mathrm{~min}$ post, $5 \mathrm{~min}$ post fatigue; $15 \mathrm{~min}$ post, $15 \mathrm{~min}$ post fatigue; $60 \mathrm{~min}$ post, $60 \mathrm{~min}$ post fatigue. (1)-(5) represent mean \pm SD. The values in parentheses represent rates of change when the values before fatigue are considered $100 \%$

increase muscle recovery time compared with voluntary isometric contraction exercises.

The total trajectory length indicates the center of pressure trajectory during static balance, which affects balance function. The total trajectory lengths increased significantly when hip extensors and ankle plantar flexors were fatigued, indicating a significant decline in balance function. Hip extensors, which act as antigravity muscles, are important for maintaining a standing position. This reinforces that a hip strategy ${ }^{21-23)}$ is used to control static standing balance.

It has been reported that a hip strategy plays a larger role for seniors in maintaining posture, while young adults depend more on an ankle strategy ${ }^{23)}$. Our ankle plantar flexor results also indicate that an ankle strategy ${ }^{21-23)}$ with high proprioceptive posture control is more significant for maintaining a standing position in healthy young adults than in the elderly. Although there was a significant increase in the total trajectory length of both hip extensors and ankle 
plantar flexors immediately after muscle fatigue, this did not increase further and resulted in a decline in balance function for only a short time. The short time of decline in balance function was presumably because the subjects were healthy young adults with a good ability to recover from muscle fatigue $^{14,24-26)}$

Trajectory length per unit area is said to be an indicator of the degree of proprioceptive posture control ${ }^{17)}$. The trajectory length per unit area of hip flexors, hip extensors, knee flexors and ankle dorsiflexors decreased significantly after fatigue. It is assumed that the impacts on these muscle groups suppressed the posture control mechanisms of the proprioceptive reflexes in each joint ${ }^{27)}$ and consequently weakened balance function. This study found that fatigue of hip extensors in particular caused a continuous decline in balance function, as has also been previously reported ${ }^{28)}$. Consideration of only the changes in total trajectory length suggests that balance function decreases only temporarily after muscle fatigue. However, consideration of the changes in trajectory length per unit area suggests that fatigue of hip extensors causes a longer decline in balance function. Based on these results, we think it is critical to consider changes in the trajectory length per unit area when verifying overall results, as judging balance function using only the total trajectory length may be inaccurate.

Hip extensors are important for maintaining a standing position, and fatigue of this muscle group on one side had an impact on balance function. When a person falls backwards, postural reflexes cause dorsiflexion of both ankles and extension of the hip on one side. This is an innate human reflex involving stimulation of tactile receptors on the sole of the foot and proprioceptive reflexes of the ankle joints to control posture. As the body falls backwards, signals from the tactile receptors on the sole cause ankle dorsiflexion and hip extension, resulting in body movements that prevent falling and maintain posture. When this postural reflex mechanism is considered, there is an obvious risk of falling when there are difficulties with ankle dorsiflexion or hip extension.

It has previously been shown that balance function can be evaluated in healthy adults and patients using a stabilometer ${ }^{29,30)}$. This study used a stabilometer to show that among lower limb muscle groups, the hip extensors exert the most significant influence on balance function. However, this study only investigated healthy young adults. Further investigation is necessary to determine if these results apply to the elderly. Moreover, as the methods we used to fatigue muscles and the position of our sight target were different from those of previous studies, the effects of fatigue on ankle joint muscles should be verified.

It is apparent that seniors have a higher risk of falls in their daily lives due to a decline in balance function with aging. Various balance training methods have been suggested as preventive measures against falls. Almost all of the past reports suggested combination training programs including several exercises, but they did not specify which muscles should be the main focus. The findings of this study indicate that it would be beneficial to adopt a balance training program that focuses on strengthening hip extensors.

\section{REFERENCES}

1) Weir E, Culmer L: Fall prevention in the elderly population. CMAJ, 2004 171: 724. [Medline] [CrossRef]

2) McMurdo MET, Miller AM, Daly F: A randomized controlled trial of fall prevention strategies in old peoples' homes. Gerontology, 2000, 46: 83-87. [Medline] [CrossRef]

3) Westlake KP, Wu Y, Culham EG: Sensory-specific balance training in older adults: effect on position, movement, and velocity sense at the ankle. Phys Ther, 2007, 87: 560-568. [Medline] [CrossRef]

4) Rogers ME, Fernandez JE, Bohlken RM: Training to reduce postural sway and increase functional reach in the elderly. J Occup Rehabil, 2001, 11: 291-298. [Medline] [CrossRef]

5) $\mathrm{Wu} \mathrm{G}$ : The relation between age-related changes in neuromusculoskeletal system and dynamic postural responses to balance disturbance. J Genront A Biol Sci Med Sci, 1998, 53: 320-326.

6) Morley JE: A fall is a major event in the life of an older person. J Genront A Biol Sci Med Sci, 2002, 57: 492-495.

7) Seidler RD, Martin PE: The effects of short term balance training on the postural control of older adults. Gait Posture, 1997; 6: 224-236. [CrossRef]

8) Chaudhuri S, Aruin AS: The effect of shoe lifts on static and dynamic postural control in individuals with hemiparesis. Arch Phys Med Rehabil, 2000, 81: 1498-1503. [Medline] [CrossRef]

9) Wolf B, Feys H, Weerdt WD, et al.: Effect of physical therapeutic intervention for balance problems in the elderly; a single-blind, randomized, controlled multicentre trial. Clin Rehabil, 2001, 15: 624-636. [Medline] [CrossRef]

10) Kammerlind AS, Hakansson JK, Skogsberg MC: Effects of balance training in elderly people with nonperipheral vertigo and unsteadiness. Clin Rehabil, 2001, 15: 463-470. [Medline] [CrossRef]

11) Brooks VB: Cerebellar functions in motor control. Hum Neurobiol, 1984 2: 251-260. [Medline]

12) Horak FB, Nashner LM, Diener HC: Postural strategies associated with somatosensory and vestibular loss. Exp Brain Res, 1990, 82: 167-177. [Medline] [CrossRef]

13) Enbom H, Magnusson M, Pyykkö I, et al.: Presentation of a posturographic test with loading of the proprioceptive system. Acta Otolaryngol Suppl, 1988, 455: 58-61. [Medline] [CrossRef]

14) Yaggie JA, McGregor SJ: Effects of isokinetic ankle fatigue on the maintenance of balance and postural limits. Arch Phys Med Rehabil, 2002, 83: 224-228. [Medline] [CrossRef]

15) Gribble PA, Hertel J: Effect of lower-extremity muscle fatigue on postural control. Arch Phys Med Rehabil, 2004, 85: 589-592. [Medline] [CrossRef]

16) Vuillerme N, Burdet C, Isableu B, et al.: The magnitude of the effect of calf muscles fatigue on postural control during bipedal quiet standing with vision depends on the eye-visual target distance. Gait Posture, 2006, 24 169-172. [Medline] [CrossRef]

17) Kapteyn TS, Bles W, Njiokiktjien CJ, et al.: Standardization in platform stabilometry being a part of posturography. Agressologie, 1983, 24: 321-326. [Medline]

18) Portnoy H, Morin F: Electromyographic study of postural muscles in various positions and movements. Am J Physiol, 1956, 186: 122-126. [Medline]

19) Shankar S, Gander RE, Brandell BR: Changes in the myoelectric signal (MES) power spectra during dynamic contractions. Electroencephalogr Clin Neurophysiol, 1989, 73: 142-150. [Medline] [CrossRef]

20) Arendt-Nielsen L, Mills KR, Forster A: Changes in muscle fiber conduction velocity, mean power frequency, and mean EMG voltage during prolonged submaximal contractions. Muscle Nerve, 1989, 12: 493-497. [Medline] [CrossRef]

21) Nashner LM: Fixed patterns of rapid postural responses among leg muscles during stance. Exp Brain Res, 1977, 30: 13-24. [Medline] [CrossRef]

22) Horak FB, Shupert CL, Mirka A: Components of postural dyscontrol in the elderly: a review. Neurobiol Aging, 1989, 10: 727-738. [Medline] [CrossRef]

23) Manchester D, Woollacott M, Zederbauer-Hylton N, et al.: Visual, vestibular and somatosensory contributions to balance control in the older adult. J Gerontol, 1989, 44: M118-M127. [Medline]

24) Woollacott MH, Shumway-Cook A, Nashner LM: Aging and posture control: changes in sensory organization and muscular coordination. Int J Aging Hum Dev, 1986, 23: 97-114. [Medline] [CrossRef]

25) Woollacott M, Inglin B, Manchester D: Response preparation and posture control. Neuromuscular changes in the older adult. Ann N Y Acad Sci, 1988, 515: 42-53. [Medline] [CrossRef]

26) Morioka S, Yagi F: Influence of perceptual learning on standing posture balance: repeated training for hardness discrimination of foot sole. Gait 
Posture, 2004, 20: 36-40. [Medline] [CrossRef]

27) Vuillerme N, Boisgontier M: Muscle fatigue degrades force sense at the ankle joint. Gait Posture, 2008, 28: 521-524. [Medline] [CrossRef]

28) Berger W, Dietz V, Quintern J: Corrective reactions to stumbling in man: neuronal co-ordination of bilateral leg muscle activity during gait. J Physiol, 1984, 357: 109-125. [Medline]
29) Okawa T, Tokita T, Shibata $Y$, et al.: Stabilometry - Significance of locus length per unit area (L/A) -. Equilibrium Res, 1995, 54: 296-306. [CrossRef]

30) Okawa T, Tokita T, Shibata Y, et al.: Stabilometry - Significance of locus length per unit area (L/A) in patients with equilibrium disturbances -. Equilibrium Res, 1996, 55: 283-293. [CrossRef] 